\title{
CARACTERIZAÇÃO DA SITUAÇÃO DO CUIDADO DOS PACIENTES DIABÉTICOS NUMA UNIDADE BÁSICA \\ DE SAÚDE DE SÃO PAULO
}

Medicina Preventiva

\section{INTRODUÇÃO}

Tendo em vista a prevalência de diabetes na população brasileira, bem como os impactos da doença sobre a saúde individual e o SUS como um todo, foi realizada caracterização da situação do cuidado com os pacientes diabéticos de uma UBS de São Paulo, tendo como referência as ações preconizadas pelas políticas públicas de saúde vigentes.

\section{METODOLOGIA}

Foi realizado levantamento bibliográfico a fim de identificar as práticas preconizadas pelo MS, SES e SMS para o cuidado dos pacientes diabéticos, como as práticas preconizadas pelo Sistema QualiAB e a padronização de exames a serem solicitados periodicamente proposta pela SES-SP. O diagnóstico da situação do cuidado na UBS foi feito a partir da observação de alguns atendimentos e entrevistas com profissionais e usuários.

\section{RESULTADOS}

Observou-se que no atendimento aos pacientes nem todas as ações preconizadas são sempre desempenhadas. Além disso, da forma como é realizado o upload dos dados armazenados pelos glicosímetros fornecidos pela SMS aos usuários, informações importantes para o seu acompanhamento podem ser acessadas apenas por um único computador, e por vezes não são registradas em prontuário.

\section{PROPOSTAS}

Propõe-se a adoção de protocolo para cuidado dos diabéticos, a ser seguido a cada consulta, bem como padronização da solicitação de exames laboratoriais periódicos. Além disso, foi proposta reestruturação do procedimento de entrega de insumos para os insulinodependentes, especialmente no tocante ao registro das medições em prontuário.

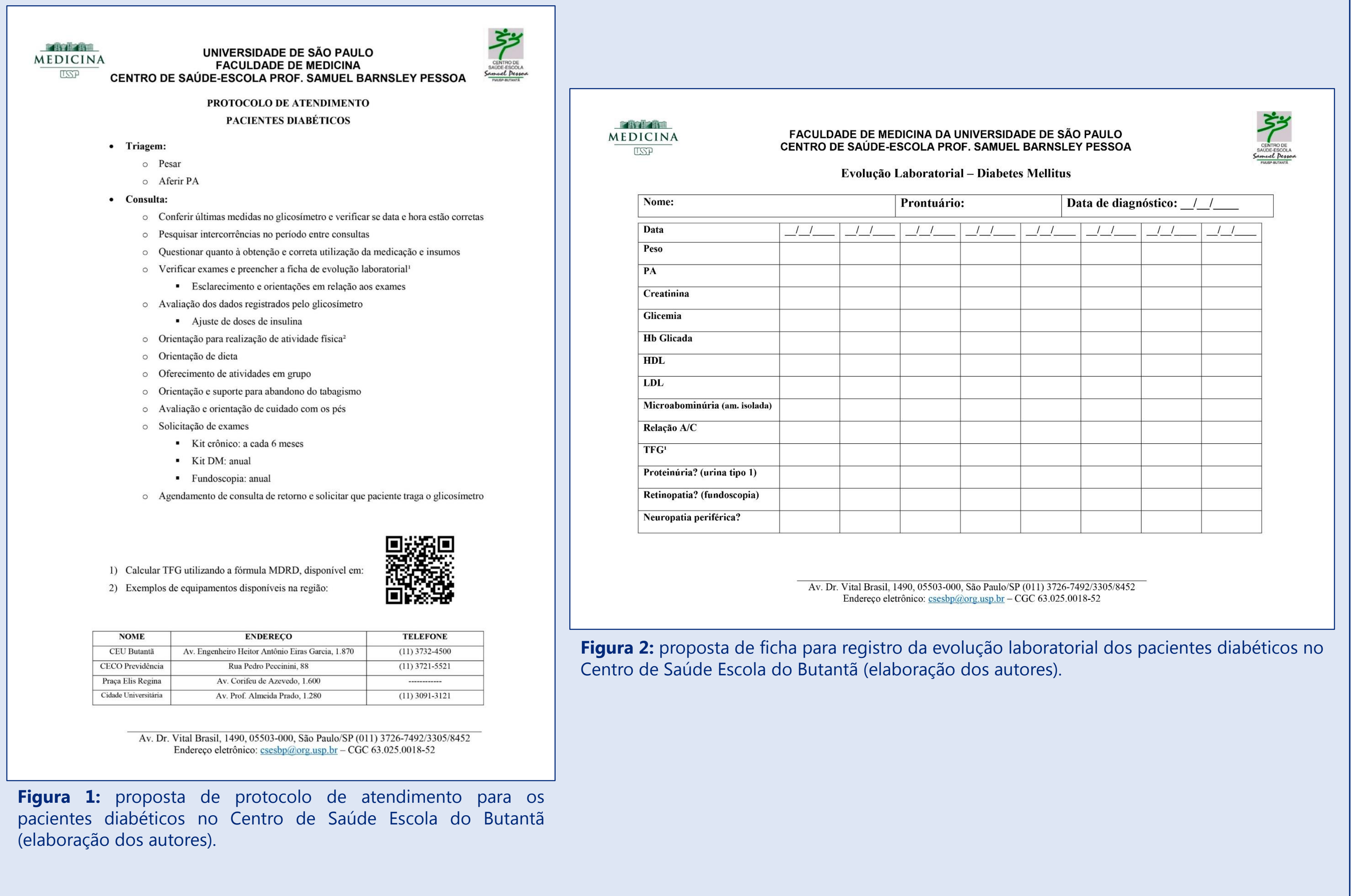

\section{REFERÊNCIAS}

1. Estratégias para o cuidado da pessoa com doença crônica: diabetes mellitus / Ministério da Saúde, Secretaria de Atenção à Saúde, Departamento de Atenção Básica. Brasília: Ministério da Saúde, 2013;

2. Caderno de boas práticas para organização dos serviços de atenção básica: Critérios e padrões de avaliação utilizados pelo Sistema QualiAB [recurso eletrônico] / Organização e autoria Elen Rose Lodeiro Castanheira ... [et at.]. Botucatu: UNESP-FM, 2016;

3. Linha de cuidado: Diabetes Mellitus. Secretaria de Estado da Saúde de São Paulo, 2010;

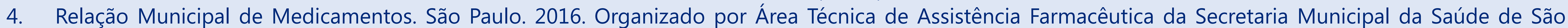
Paulo. São Paulo: Secretaria Municipal da Saúde; 2016;

5. Manual do pé diabético: estratégias para o cuidado da pessoa com doença crônica. Brasil. Ministério da Saúde. Secretaria de Atenção à Saúde. Departamento de Atenção Básica. Brasília: 2016 